\title{
The Implementation of E-campus during the Assessment of English for Specific Purposes
}

\author{
Iryna Simkova $^{1, *}$, Alina Medvedchuk ${ }^{1}$, Tetyana Vaynahiy ${ }^{2}$ \\ ${ }^{1}$ Department of English Language for Humanities, National Technical University of Ukraine "Igor Sikorsky Kyiv Polytechnic \\ Institute", Ukraine \\ ${ }^{2}$ Department of Public Health and Humanitarian Disciplines, Uzhhorod National University, Ukraine
}

Received March 11, 2020; Revised April 15, 2020; Accepted April 27, 2020

Copyright $\mathrm{O} 2020$ by authors, all rights reserved. Authors agree that this article remains permanently open access under the terms of the Creative Commons Attribution License 4.0 International License

\begin{abstract}
The paper aims to explore the results of the E-campus implementation during the assessment of English for Specific Purposes. The authors focus on the types, aims, and role of assessment in English for Specific Purposes teaching. One hundred students and 100 teachers took part in the research. This paper investigates how the teachers' and students' attitudes to English for Specific Purposes assessment can be changed due to the E-campus usage. The main functions of the assessment are analyzed. The analyses presented in the study broaden current knowledge about the impact of E-campus during summative and formative assessment in English for Specific Purposes course. The criteria for the assessment of spoken interaction knowledge, skills, and abilities during English for Specific Purposes course are discussed. The importance of hard and soft skills in students' future professional activity is estimated. E-campus is considered as one of the main aspects that help students to develop individual learning trajectories. The study provides considerable insight into the advantages of E-campus implementation during the assessment of English for Specific Purposes. The results of this study indicate that the application of E-campus during the assessment of English for Specific Purposes has a positive effect on the learning and teaching process.
\end{abstract}

Keywords English for Specific Purposes, E-campus, Formative Assessment, Summative Assessment

\section{Introduction}

Currently, Ukrainian Higher Schools have entered a new century of penetration of innovative technologies into all spheres of their life; it requires prompt and effective adaptation to the new conditions of learning and training.

Modern society needs specialists who possess not only professional knowledge that quickly becomes outdated in the ever-increasing flow of information, but also specialists who possess skills and abilities to solve professional problems.

This contradiction between the needs of modern society for highly qualified professionals, on the one hand, has an inability of contemporary education to meet these needs, on the other hand, requires further developing of different aspects of the education system, such as assessment issues, new curriculum, and syllabi design, implementation of information technology, etc.

This paper considers electronic campus (E-campus) as a key element of the university infrastructure and as a communication environment for the interaction between students, $\mathrm{PhDs}$, teachers, and researchers; it is an integral part of the learning process. E-campus was chosen because it is one of the most feasible communicative environments that is based on the use of modern IT solutions due to the dominant trends that determine the development of higher education in Ukraine, the implementation of the new information technologies, and the creation of scientific and learning/teaching space. The primary task is to achieve a new, modern quality of education, which orients towards students learning and development of their personality, their cognitive and creative abilities. The requirements for the results of mastering the new skills and abilities entailed many changes in approaches to students' assessment. 


\section{HARD SKILLS}

reading skills;

listening skills;

writing skills;

speaking skills (spoken production and spoken interaction).

\author{
SOFT SKILLS \\ critical thinking; \\ functioning on multidisciplinary teams; \\ creativity; \\ effective interaction.
}

Figure 1. The example of hard and soft skills in ESP

According to the requirements of stakeholders, modern professionals must possess "hard skills" and "soft skills". In the literature $[1 ; 2]$, "hard skills" usually refer to specialized knowledge, skills, and abilities necessary for the professional activity, while "soft skills" tend to be used to refer to the ability to work in a multidisciplinary team. They differ according to needs analysis in different specialisms. In most cases, they include critical thinking, knowledge of the ethical responsibility of making professional decisions, the ability to analyze and critically evaluate made decisions, readiness for continuing professional development, etc. English Language skills can belong to both groups of hard skills and soft skills, it depends on the specialism. Figure 1 demonstrates a small example of how hard and soft skills can be measured in the English Language for Specific Purpose (ESP) teaching.

Figure 1 shows that hard skills can be clearly demonstrated and measured, while soft skills are non-specialized but essential for a career and success in life, skills that are responsible for high productivity. In our opinion, they are "cross-cutting" and not related to a specific professional area.

Thus, the useful ESP teaching and assessment is a challenge of the time, and the high level of ESP is the key to a successful career. Teachers should use such assessment methods and techniques that will allow them to assess not only knowledge, skills and sub-skills in ESP, but also students' creative thinking, team-work skills, readiness for continuing professional development, academic mobility, life-long learning, etc.

Assessment should include two aims: the final fixing of students' achievements and the development of necessary hard and soft skills. It is assumed the use of various methods and forms of assessment in ESP. In addition, the designers of curriculum and syllabus are responsible for education quality assurance; hence an integral part of any ESP syllabi is the criteria aimed at the assessment of the dynamics of students' individual achievements. Whereas during ESP assessment, teachers need to consider different skills in reading, listening, writing and speaking, the integrated approach to the assessment of students' results had to be used. In ESP language learning, the assessment is considered as correlating of the results achieved by students in ESP with preliminary set goals [3].
The main functions of the assessment are intelligential, controlling, motivational, and educational (Table 1). Analyzing the quantitative assessment system adopted in Ukrainian Higher schools, we admit that it does not always fulfill the above functions. As a result, there are certain contradictions between the continuous educational process and fragmentation assessment process, between the urgent need to develop a reliable system for assessing students' achievements and insufficient analytical data about students' progress, the necessity to create the individual learning trajectory for every student and lack of teachers' theoretical knowledge of the assessment system to provide students with their individual learning trajectory.

Table 1. The main functions of assessment and their aims

\begin{tabular}{|l|l|}
\hline $\begin{array}{l}\text { NAME } \\
\text { FUNCTION }\end{array}$ & AIM OF FUNCTION \\
\hline INTELLIGENTIAL & $\begin{array}{l}\text { it broadens students view on ESP and } \\
\text { affects the students' individual learning } \\
\text { trajectory; }\end{array}$ \\
\hline CONTROLLING & $\begin{array}{l}\text { it provides continuous monitoring of } \\
\text { students' achievements and influences, } \\
\text { the quality of performed tasks, and } \\
\text { develops students' critical attitude to task } \\
\text { performance; }\end{array}$ \\
\hline MOTIVATIONAL & $\begin{array}{l}\text { it stimulates students' activity during } \\
\text { classes and brings stimulus to life-long } \\
\text { learning; }\end{array}$ \\
\hline EDUCATIONAL & $\begin{array}{l}\text { it provides students with the knowledge } \\
\text { and develops students' critical attitude to } \\
\text { task performance. }\end{array}$ \\
\hline
\end{tabular}

Besides, there is one more challenge: the weak connection between the objective nature of assessment and an inability to design a holistic forecast of the student's individual learning trajectory based on assessment results and, as a result, a failure to make recommendations on the development of individual learning trajectory. By exploring the next contradictions, we were able to adopt E-campus for ESP assessment needs. It is a socially oriented, accessible, manageable, and technologically advanced educational system (space); it is created due to the integrated use of the modern wireless communication achievements, advanced technologies, and support of different information resources. 


\begin{tabular}{|c|c|c|c|c|c|c|c|c|c|}
\hline № & & Name & $\Sigma$ & ECTS & $4 / 09$ & $11 / 09$ & $18 / 09$ & $25 / 09$ & $02 / 10$ \\
\hline 1 & $\mathrm{X}$ & Evgeniya & 96 & A & 5 & 5 & 5 & 5 & 5 \\
\hline 2 & $X$ & Daryna & 95 & A & 5 & 5 & 5 & 5 & 5 \\
\hline 3 & $\mathrm{X}$ & Yuriy & 86 & B & 4 & 5 & 1 & 4 & 5 \\
\hline 4 & $\mathrm{X}$ & Alexandra & 70 & D & 4 & 4 & 3 & 4 & 3 \\
\hline 5 & $\mathrm{X}$ & Anastasiia & 99 & A & 5 & 5 & 5 & 5 & 5 \\
\hline 6 & $X$ & Olga & 75 & $\mathrm{C}$ & 4 & 5 & 3 & 4 & 4 \\
\hline 7 & $X$ & Anna & 78 & $\mathrm{C}$ & 4 & 5 & 3 & 3 & 4 \\
\hline 8 & $\mathrm{X}$ & Kyryl & 95 & A & 5 & 5 & 5 & 5 & 5 \\
\hline 9 & $\mathrm{X}$ & Alina & 70 & D & 3 & 3 & 2 & 3 & 3 \\
\hline 10 & $\mathrm{X}$ & Serhii & 75 & $\mathrm{C}$ & 4 & 4 & 4 & 4 & 3 \\
\hline 11 & $\mathrm{X}$ & Tetyana & 85 & B & 4 & 5 & 4 & 4 & 5 \\
\hline 12 & $\mathrm{X}$ & Kyrylo & 65 & E & 2 & 3 & 3 & 2 & 2 \\
\hline 13 & $X$ & Igor & 85 & B & 4 & 5 & 5 & 4 & 4 \\
\hline
\end{tabular}

Figure 2. The example of E-campus usage during the assessment of bachelor students

E-campus allows us to assess and develop the knowledge, skill, and abilities of students in ESP. This rating system is based on the combined use of two types of assessment: formative and summative (Figure 2). It presents the data of students' progress with general grades $\left(\sum\right)$ for the semester and examples of grades for five weeks of studying. Formative assessment refers to the assessment during the learning process when students analyze knowledge, skills, and abilities. It includes feedback showing the progress or regress in students' learning. The primary purpose of this assessment is to motivate the students to lifelong learning, develop their critical thinking and cognitive skills.

Black and William [3] draw out our attention that the main feature of formative assessment is the use of the techniques and methods that lead to an improvement in the quality of students' knowledge, skills, and subskills. Formative assessment is considered as a feedback tool for teachers and students. In their groundbreaking paper of 1997, Harlen and James [4] suggested that formative assessment results allow all participants of the learning and teaching process to assess the current state of learning and identify ways of further development and individual learning trajectory. According to Shepard [5], formative assessment is useful, provided that its results are immediately used to identify new ways and forms of learning. During the process of formative assessment forms, techniques, and methods don't matter. The assessment is formative due to the aim of realization rather than a set of specific tasks.

An analysis of recent findings regarding formative assessment has led to the suggestion that assessment will be formative if it meets the following terms: assessment tasks correspond to the topics of the syllabus; they are familiar and appropriate to students in forms and content; they are designed in such a way as they help to identify learning problems of each student and stimulate the process of students' reflection. Thanks to the usage of E-campus, the results of the formative assessment are immediately available to the teacher and students. It gives teachers and students a chance to plan learning activity and individual learning trajectory based on the results of the assessment and improves the quality of their knowledge. We define the individual learning trajectory as a personal way of studying when students can realize their potential in education.

In the E-campus, we can track the continuous learning process and the process of formative assessment. E-campus gives a possibility to assess the learning process while passing specific topics as well. While working with E-campus ESP teachers can assess the development of students' achievements, and students can track their own progress.

Summative assessment is carried out in order to determine the correspondence of students' knowledge to the requirements of the curriculum and state the fact of student's learning. In contrary to formative assessment that is carried out by the participants of the learning process and with the frequency that is necessary for the teacher and students to achieve learning goals, the summative assessment is carried out by external experts following a particular curriculum and syllabus requirements. In the investigation dedicated to assessment, Berman [6] shows that in formative assessment, the assessment scale can be developed by the teacher or a group of teachers; in summative assessment, the generally accepted state assessment scale is used.

There are several approaches to conducting the 
formative assessment. At the first stage, William and Black [3] suggest determining the students' intentions and assessment criteria. Then it is necessary to organize sufficient work in the class, create the feedback that ensures the students' individual learning trajectory, enhance the work of students in groups and pairs for peer-assessment and explain to students that they are the active participants of the learning process. They draw our attention to the importance of determining the learning outcomes. The second stage focuses on the creative activities that help students to achieve the outcomes. In the third stage, the authors propose using feedback as a powerful stimulus for the achievement of results [6]. At the first stage of assessment, Leighton [7] offers to transfer goals into measurable learning outcomes, determine the needed achievement level, select assessment techniques, select and implement appropriate teaching methods, conduct assessments and determine if the learning outcomes are achieved.

The aim of the paper is to investigate the results connected with the implementation of E-campus during the ESP assessment.

\section{Materials and Methods}

To achieve the goals of the study, the empirical and theoretical methods were used.

\subsection{General Background of Research}

The theoretical methods used in the study are the generalization of pedagogical and linguistics literature to consider the theoretical backgrounds of assessment; the comparative analysis to stipulate the distinctive features of summative and formative assessment; the description of the results to explain the effect of E-campus assessment implementation in ESP teaching.

The empirical methods used in the paper are the observation of E-campus assessment during the learning process, the quantitative and qualitative analysis of the survey to stipulate the positive or negative effects of E-campus implementation during EPS learning, Fisher's Exact Variance Test (F-test) [8] for verification of results.

\subsection{Participants}

To illustrate the positive and negative effects of the implementation of E-campus during ESP assessment, the survey was carried out among 100 ESP teachers and 100 students of different specialism.

The survey was conducted from November to December 2019. The sample was divided into two groups: groups of students (ST) and a group of teachers (TE). The participants in different groups must answer different kinds of questions. Representatives of the TE group were asked to determine the place and role of formative assessment in the ESP teaching process, to identify the main difficulties that impede the formative assessment, to determine the scope of its application and the necessary conditions for effective use.

Representatives of the ST group were asked to express their attitude to different kinds of assessment proposed by E-campus, to determine the place and role of formative assessment in the ESP learning, to identify the main benefits of E-campus assessment and how motivational it is for their individual learning trajectory development.

\subsection{Instrument and Procedures}

As was mentioned to verify the results of the implementation of E-campus during ESP assessment, the survey was used.

The study employed a qualitative and quantitative analysis of data collected from survey and assessment observations.

As was mentioned, the F-test (Fisher's Exact Variance Test) was used to verify the positive or negative effects of E-campus implementation during EPS learning.

The initial data for the application of the F-test are presented in Table 2. It contains the results given by students before and after the implementation of the E-campus for ESP assessment. For the reason of simplicity, the students' sample was divided into sample 1 (students before the E-campus implementation) and sample 2 (students after the E-campus implementation), and ranged accruing to the level of satisfaction shown by students. We consider the results presented by students in different testing groups (TG-1, TG-2, TG-3, and TG-4) before the implementation of the E-campus to be sample 1, and results presented after the application of the E-campus to be sample 2 .

In order to calculate the results received before and after the implementation of the E-campus for ESP assessment, we have formulated statistical hypotheses, which assume the null (H0) and alternative (H1) hypotheses:

H0: the results presented in sample 1 stipulate that quantity of students satisfied with the ESP assessment before the implementation of the E-campus are higher than the number of students, who are satisfied with the ESP assessment after the implementation of the E-campus;

H1: the results presented in sample 1 stipulate that quantity of students satisfied with the ESP assessment before the implementation of the E-campus are lower or equal to the number of students who are satisfied with the ESP assessment after the implementation of the E-campus. 
Table 2. The empirical frequencies of students' sample

\begin{tabular}{|c|c|c|c|c|c|}
\hline \multirow{2}{*}{ Results } & \multicolumn{3}{|c|}{ «effect present» } & «effect absent» & \multirow{2}{*}{$\begin{array}{c}\text { The total quantity of } \\
\text { students }\end{array}$} \\
\cline { 2 - 5 } & Quantity of students & $\%$ & $\varphi$ & Quantity of students & 100 \\
\hline Before & 8 & $8 \%$ & 0,56 & 92 & 100 \\
\hline After & 92 & $92 \%$ & 2,50 & 8 & 92 \\
\hline
\end{tabular}

Above, we create the table of empirical frequencies of students' samples according to two variances: «effect present» and «effect absent».

As we can see, only eight students were satisfied with the EPS assessment results before the implementation of the E-campus. That is why we put 8 to the first higher column. Ninety-two students were not satisfied with the EPS assessment results before the implementation of the E-campus. So, we put 92 to the lower column.

To define the F-test, we use equation (1):

$$
\varphi=2 \arcsin \sqrt{ } p
$$

where $\varphi$ - central angel value,

$\mathrm{p}$ - percentage value.

$$
\begin{aligned}
& \varphi^{* 1}=2 \arcsin \frac{\sqrt{8}}{92}=0,56 \\
& \varphi^{*} 2=2 \arcsin \frac{\sqrt{92}}{100}=2,50
\end{aligned}
$$

We find the empirical F-test $\varphi^{*}$ emp using equation (2):

$$
\varphi^{*} \mathrm{emp}=\left(\varphi^{*} \max -\varphi^{*} \min \right) / \frac{\mathrm{n} 1 \cdot \mathrm{n} 2}{\mathrm{n} 1+\mathrm{n} 2}
$$

In this equation

$\varphi^{*} \max$ means an angle corresponding to the bigger percentage,

$\varphi^{*}$ min means angle corresponding to a smaller percentage,

$\mathrm{n} 1$ means the number of students in sample 1 ,

$\mathrm{n} 2$ means the number of students in sample 2 .

$\ln ^{*}$ emp $=(2,50-0,56) \frac{\text { our }}{\frac{100 \cdot 100}{100+100}}=13,71$

research

Critical values of F-test we can find in the table for F-test variances (3)

$$
\varphi^{*} \text { crit }=\left\{\begin{array}{r}
1,64(\mathrm{p} \geqslant 0,05) \\
2,50(\mathrm{p} \geqslant 0,01)
\end{array}\right.
$$

To compare the critical value with the empirical value, we can stipulate

$$
\begin{gathered}
\varphi^{*} \text { crit }(0,01)<\varphi^{*} \mathrm{emp} \\
2,50<13,71
\end{gathered}
$$

Figure 3 with the axe of significant zones, demonstrates just how significant is the obtained results.

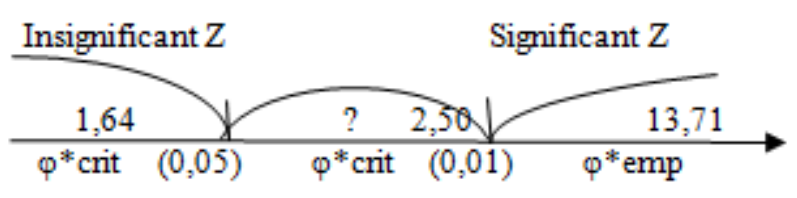

Figure 3. The F-test presentation in order to prove the validly of the results received during the survey

These results are significant as far as the empirical value of the F-test belongs to Significant Zone. Figure 3 confirms that we adopt alternative hypothesis where the results presented in sample 1 and sample 2 stipulate that quantity of students satisfied with the ESP assessment before the implementation of the E-campus are lower or equal to the number of students, who are satisfied with the ESP assessment after the implementation of the E-campus. In our view, the result emphasizes the effectiveness of the implementation of the E-campus for ESP assessment.

The survey results before the implementation of the E-campus for ESP assessment showed that even though $77 \%$ of respondents (teachers and students) agree that formative assessment takes an essential role in the learning process, $92 \%$ of students were unsatisfied with the quality and objectivity of ESP assessment. In comparison, $82 \%$ of teachers were dissatisfied with the time-consuming process of ESP assessment. Unexpectedly that only $48 \%$ of respondents (teachers) may determine the scope of its application, and only $38 \%$ of respondents (teachers) may present the necessary conditions under which the formative assessment has to be used. The most striking result to emerge from the survey is that almost $95 \%$ of respondents (teachers and students) state that using E-campus in assessment helps them to overcome the main difficulties that impede the formative assessment. Among the main challenges hindering the systematic use of formative assessment is mentioned: the lack of time for its implementation (62\% of teachers) and lack of motivation (75\% of students).

Significantly, the majority of respondents $(85 \%$ of students) believe that one of the main benefits of E-campus assessment is quick feedback from the teacher that can be considered as a prerequisite for the implementation of an individual approach to students and increasing the motivation of students to learn.

\section{Results and Discussion}

E-campus is a vital infrastructure element with a cycle 
of automation of the essential tasks of the university, providing students with personal information space, individual learning trajectory, and related information services. Due to the learner-centered approach used in E-campus, the teachers and students jointly determine the criteria for grading and assessment.

The criteria of assessment, the time of grading, methods, and techniques are determined by the teacher based on the set goals. There are several methods and techniques for formative assessment. They can be divided into two kinds: result assessment techniques and process assessment techniques. In an attempt to implement E-campus for ESP assessment, we use it during the learning process (lesson) and after students passing a particular topic, activity, etc. We chose E-campus on account of the fact that it enables teachers to use universal assessment (soft skills during ESP learning) and particular assessment (language skills during ESP learning). Moreover, assessment can also be divided into the interrelated assessment of different kinds of activities (reading, listening, speaking, and writing) as far as universal assessment is divided into assessment made by teachers, self-assessment, peer assessment, and mixed assessment. Thus, E-campus provides students with different opportunities for formative assessment.

With that help of E-campus, teachers may download guidelines necessary for formative assessment, individual tasks that students may use considering the results of their assessment. There is a strong probability that it stimulates teachers to share their banks of techniques, forms, methods of formative assessment with their colleagues and students, and consequently, it helps students to develop their individual learning trajectory.

The individual task in ESP in Fig. 4 demonstrates the assignment and what kinds of students' skills in ESP and soft skills (team-work skills) can be measured. Teachers submitted tasks to students via E-campus. Students are proposed to work in groups, role-play a small discussion between three representatives who visited "Big Energy Summit", record and send to teachers their role-plays. This task showed how students could learn to work in groups, use their analysis and synthesis skills, and practice spoken interaction skills.
Different scholars draw our attention to the idea that approaches used to assess the knowledge, skills, and abilities in ESP are sensitive to the type of activity (reading, listening, speaking, or writing). However, most of the researches $[9 ; 10 ; 11]$ consider that criteria using for ESP assessment are closely connected with the goal of ESP learning and should reflect the characteristics that the ESP learning is aimed at. A recent review of the literature $[9 ; 11]$ on this topic found that the leading criterion of the high-level performance of an activity in ESP is the successful accomplishment of a communicative task, which includes soft and hard skills usage.

For instance, a number of studies $[9 ; 11 ; 12]$ have found that the main criteria to assess the spoken interaction in ESP are: 1) relevance to the professional situation; 2) communicative sufficiency; 3) sufficient reactivity and initiative 4) argumentation; 5) usage of cliché; 6) language fluency.

Various approaches $[12 ; 13]$ have been proposed to distinguish qualitative as basic and quantitative as additional criteria for the assessment of spoken interaction.

The main quantitative criteria include the volume of expressions and the pace of interaction.

The implementation of E-campus enables the assessment of additional criteria. For instance, the spoken interaction in ESP may be assessed according to such criteria as the degree of professional and functional adequacy of utterances, the use of terminology during the interaction, creative thinking, team-work skills, etc.

Among assessment criteria for teamwork, we propose to consider the ability of students to give arguments, the ability of students to compare, the ability of students to interact in the team, the logic of answer and presentation, and the cultural behavior during spoken interaction in general.

So, the performance of the task in Figure 4 can help teachers to assess such soft skills as students' level of argumentation, level of interaction and cooperation during communication, and help students to follow their progress, improve knowledge in terminology and usage of cliché, language fluency, and increase the logic of presentation. 


\begin{tabular}{|c|c|c|c|}
\hline \multicolumn{4}{|c|}{$\begin{array}{l}\text { Participant A and participant B: You are British or foreigners who speak only English. You've arrived to "Big Energy Summit" to meet } \\
\text { representatives from the Ukrainian organization. Find out your personal history from the chart. Give information about your organization. } \\
\text { Choose a name. }\end{array}$} \\
\hline HEADQUARTERS & MANCHESTER & BRUSSELS & LONDON \\
\hline Name of the organization & Radiant Solar Ltd. & Energy Star Corporation & $\begin{array}{l}\text { National Dialogue Initiative } \\
\text { GEF }\end{array}$ \\
\hline Main activities & $\begin{array}{l}\text { It creates energy efficiency } \\
\text { buildings. }\end{array}$ & $\begin{array}{l}\text { It sells energy-efficient } \\
\text { products. }\end{array}$ & $\begin{array}{l}\text { It deals with biodiversity and } \\
\text { climate change. }\end{array}$ \\
\hline Secondary activities & $\begin{array}{l}\text { It builds capacity for the } \\
\text { implementation of } \\
\text { Cartagena Protocol } \\
\text { Biosafety. }\end{array}$ & $\begin{array}{l}\text { It catalyzes the sustainability of } \\
\text { protected area systems. }\end{array}$ & $\begin{array}{l}\text { It collaborates closely with } \\
\text { other treaties and agreements to } \\
\text { reach common goals } \\
\text { (International Waters, Montreal } \\
\text { Protocol). }\end{array}$ \\
\hline & & 2 & \\
\hline Types o & $\begin{array}{l}\text { small Grants Programme (up to } \\
\$ 50,000 / \text { project). }\end{array}$ & $\begin{array}{l}\text { project Development } \\
\text { (preparation) Funds } \\
\text { PDF-A up to } \$ 25,000 \text { (up to } \\
\$ 50,000 \text { ) } \\
\text { PDF-B up to } 350,000 \\
\text { PDF-C up to } \$ 1 \text { million. }\end{array}$ & $\begin{array}{l}\text { full-size projects (over } \$ 1 \\
\text { million) \& } \\
\text { Medium-sized projects (up to } \\
\$ 1 \text { million). }\end{array}$ \\
\hline Future plans of the company & $\begin{array}{l}\text { It finances renewable } \\
\text { energy/energy efficiency. }\end{array}$ & $\begin{array}{l}\text { It promotes energy-efficient } \\
\text { products/ processes. }\end{array}$ & $\begin{array}{l}\text { It provides strategic guidance } \\
\text { for GEF funding of climate } \\
\text { change projects. }\end{array}$ \\
\hline \multicolumn{4}{|c|}{$\begin{array}{l}\text { Participant C: You are a Ukrainian representative. Discuss with your foreign colleagues their plans for the future. What questions would } \\
\text { you ask your foreign partners about them? Find out: } \\
\text { - } \\
\text { - } \quad \text { whe name of their organization; } \\
\text { - } \quad \text { what the secondary activities of the organization are; } \\
\text { - } \quad \text { what types of projects they realize; } \\
\text { - } \\
\text { - } \\
\text { - } \quad \text { whether many projects they realized; } \\
\text { what their plans for future collaboration with your organization are. }\end{array}$} \\
\hline
\end{tabular}

Figure 4. The example of a task that can be submitted via E-campus to assess ESP speaking skills and team-work skills

\begin{tabular}{|c|c|c|c|c|c|c|c|c|c|}
\hline № & & Group & $\sum$ & ECTS & $\begin{array}{c}\text { Logic of } \\
\text { presentation }\end{array}$ & $\begin{array}{c}\text { Correctness of } \\
\text { presentation }\end{array}$ & $\begin{array}{c}\text { Civility during } \\
\text { interaction }\end{array}$ & $\begin{array}{c}\text { Comments } \\
\text { of other } \\
\text { teams }\end{array}$ & $\begin{array}{c}\text { Level of } \\
\text { cooperation }\end{array}$ \\
\hline 1 & $\mathrm{X}$ & Group 1 & 96 & $\mathrm{~A}$ & 25 & 25 & 21 & 25 & 25 \\
\hline 2 & $\mathrm{X}$ & Group 2 & 95 & $\mathrm{~A}$ & 24 & 25 & 20 & 6 & 20 \\
\hline 3 & $\mathrm{X}$ & Group 3 & 86 & $\mathrm{~B}$ & 20 & 20 & 20 & 6 & 20 \\
\hline 4 & $\mathrm{X}$ & Group 4 & 70 & $\mathrm{D}$ & 15 & 18 & 16 & 5 & 16 \\
\hline 5 & $\mathrm{X}$ & Group 5 & 75 & $\mathrm{C}$ & 17 & 19 & 16 & 7 & 16 \\
\hline
\end{tabular}

Figure 5. The example of teamwork assessment in E-campus

An additional application of E-campus is that it lets teachers assess each student individually or the work of the team. Then assessment criteria indicate points to evaluate group work, for example, the correctness of presentation (introduction, main body, conclusion), the logic of presentation (coherence and cohesion), civility during the interaction, comments of other teams (peer assessment is using), level of cooperation (Figure 5).

The most common qualitative indicators of spoken interaction assessment in ESP include 1) relevance to the professional situation; 2 ) sufficient reactivity and initiative; 3) the usage of specific cliché; 3) sufficient argumentation; 4) language fluency.

There is a considerable amount of literature $[10 ; 13 ; 14]$ on the selection of criteria for the spoken interaction knowledge, skills, and abilities assessment. Dudley-Evans [15] in 2009 proposed considering the extrinsic peculiarities of ESP: the ability to analyze the facts and phenomena that relate to the professional activity, the ability to treat effectively professional information, etc.

The criterion of "relevance to the professional situation" can be found as the leading one in $[15 ; 16]$. Our perception of the relevance to the professional situation is fully compliant with Emmer and Sabornie's research, where it is considered as a performance by students of communicative intentions and communicative tasks due to the certain professional situation [17].

It has been suggested [15] that "sufficient reactivity and initiative" is also an important criterion for ESP skills assessment since spoken interaction requires two-way 
communication. In order to achieve effective interaction, students should be able to initiate a spoken interaction, respond to the partners' arguments, encourage each other to continue the interaction, etc.

The criterion "sufficient argumentation" incorporates the most important elements belonging to the spoken interaction in ESP. In most professional situations, to provide reasons or arguments is a necessary skill. When discussing a controversial issue, the participants should be ready presenting his or her opinion, argue for and against the debatable issue.

The criterion "usage of cliché" implies that students can choose clichés and use them in a sufficient number and adequately to a professional situation. Thus, this criterion is also an indicator that shows how students can manage the usage of cliché and how relevant they are to a specific professional situation. Dudley-Evans's [15] findings appear to support this idea.

The experts [9;11] highlight criterion "language fluency" and suggest paying students' attention only to the significant errors that are impediments to interaction, such errors may occur on any level as grammar illiteracy, phonetic inaccuracy, insufficient vocabulary, inadequate terminology, etc.

The task in Figure 6 demonstrates assignments that promote students' development of creative skills, organizational skills, and aim at practice in writing and speaking. After drawing a collage, the students send it to the teacher via E-campus.

To assess task on Figure 6, we propose teachers to include in creative skills assessment several components: the analytical component (the logic of information presented in collage, ability to differentiate data, etc.); the emotional component (the affective evaluation of collage, the intensity of collage, etc.); the productive component (originality of ideas, synthetic skills, etc.).

Thus, as it was previously mentioned, the level of soft skills should be developed as well as hard skills, and E-campus makes it possible to monitor the progress in hard and soft skills development systematically.

At the same time, since 2016 the participation of the most quantity of Ukrainian higher schools in British Council's project "English for Universities" enable ESP teachers to develop transparent assessment system of students' knowledge, skills, and abilities as well as techniques and formative assessment methods [18]. The evidence from this study suggests that most respondents admit the positive results of the implementation of E-campus during the ESP assessment and are ready to use it on a sustainable base (Figure 7).

When are you the leader of the discussion, which plan will you choose to conduct it?
Look at the picture. Read the leaflet.
Use the information from the link https://pacecleanenergy.org/about-pace/
and draw the collage on the topic: PACE (People's action for clean energy).
Pay attention to a) activity; b) experts needed; c) energy legislation; d) participants; e) panel discussion.

EMBRACE RENEWABLE TECHNOLOGIES, ENERGY EFFICIENCY \& CONSERVATION. THESE CHOICES ARE OUR PATHS TO PEACE and GLOBAL SECURITY.

Please support PACE by attending the events detailed in this newsletter and/or volunteering your time. It's fun, exciting, timely, AND CRITICAL! Thank you!

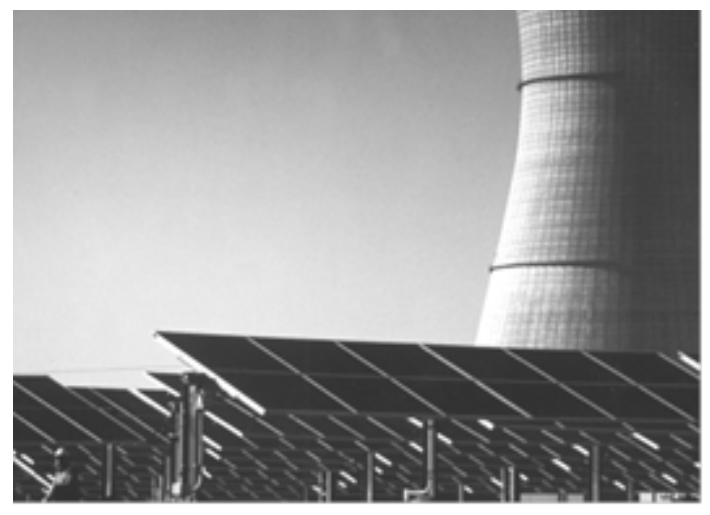

Figure 6. The example of a task that can be submitted via E-campus to assess ESP speaking and writing skills and creative skills 


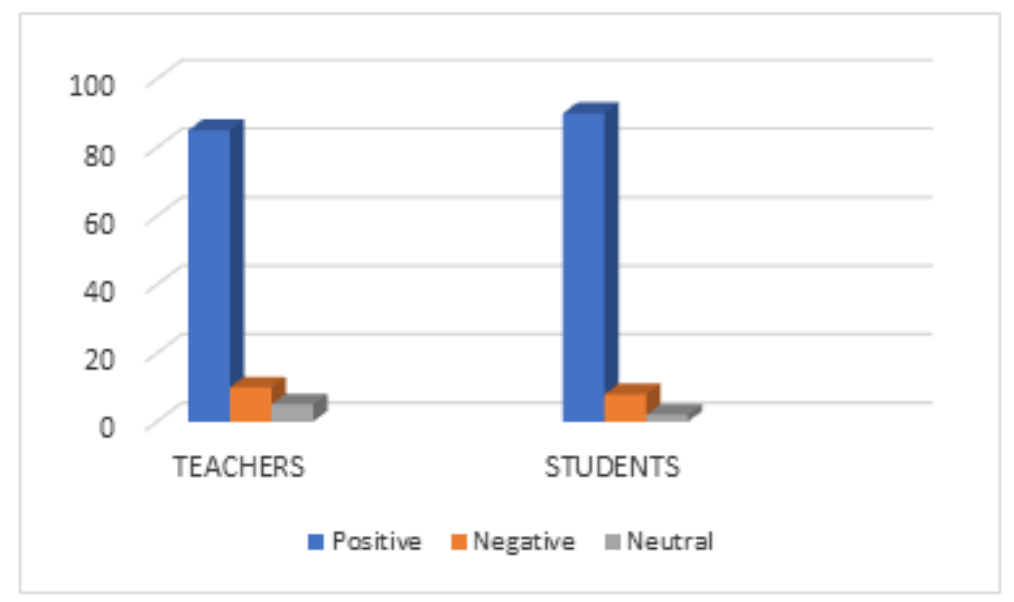

Figure 7. The attitude of teachers and students to the implementation of E-campus for ESP assessment

More recent evidence [19] shows that formative assessment in Ukrainian higher schools is strictly focused on the quality of knowledge acquired by the student, while, for example, the foreign education system in many countries states the quality of knowledge transfer. Stronge and co-workers [20] estimated that students' grades in ESP depend on their motivation, abilities, and needs; that hardly could be changed with the help of strict control performed by external controlling organizations. Surveys concerning the difficulties faced during the assessment were conducted in 2017 by a group of researchers from the focus group within the project "English for Universities" [18] demonstrate that the main problem of using assessment is related to the contradictions that arise between formative and summative assessment.

The implementation of E-campus during assessment in ESP can help teachers to overcome the contradictions between formative and summative assessments and help students to develop the individual learning trajectory.

This work revealed that one more aspect where E-campus is successfully used is the plagiarism war. With the rapid development of information and communicative technologies, the widespread usage of the Internet leads to the fact that students are surrounded by data that are difficult to correctly sort and analyze, especially when they use them to perform various creative tasks. For instance, to write essays is one of the tasks during formative assessment. Using such well-known methods and techniques of formative assessment as project-based study or case study technology, teachers should be aware that simply collecting and organizing information is not an effective assessment tool, since the information used by students can simply be copied from the Internet. In this case, students can find in their profiles in E-campus that their work contains plagiarism and can revise it as soon as possible.

Implementation of E-campus can avoid such situations as far as it is a system (space) where teachers and students can discuss each stage of work to determine what they have already done, what happened, what difficulties there are.
Also, it provides possibilities for regular use of self-assessment and peer-assessment that motivates students to gain their personal experience.

In addition, the preliminary work which was carried out several years ago [19] showed that some teachers are not ready to delegate to students their authority to assess. In this case, E-campus could help teachers who are quite reluctant to students' peer assessment and self-assessment, which are integral parts of formative assessment because it is an obligatory function in E-campus.

Bolitho and West [18] in 2017 were among those who stated that one of the frequent mistakes of teachers during the formative assessment is that they compare the results of the assessment with the high grades, while for the effective conduct of formative assessment, the results of a particular student should be compared with his/her previous results in order to state his/her personal progress. That is why E-campus is developed in such a way that students and teachers can monitor the learning progress.

In E-campus, teachers use a multi-point assessment system. It allows us to reflect in a specific point range the individual characteristics of students, and the students' efforts spent on the performance of certain types of activity are objectively assessed in points. In E-campus, students may see additional reward points for originality or novelty during completing individual tasks or solving scientific problems. They may get access to their grades regularly and at any time. Each student can choose what kind of work to do, and there is a possibility to perform additional work and get extra points.

In E-campus, teachers and students can meet directories outlined below:

1) resources, in this directory, the course curator or teacher may download different information concerning tasks or courses. These resources can be either in the form of files or in the form of external links. E-campus system enables use of various formats of electronic documents as electronic information; 
2) active elements, in this directory teachers provide means of communication between students and teachers, it may be a forum, chat, blog, etc.;

3) tasks are the elements created for students to build their individual learning trajectory. Answers to tasks may be sent to teachers in form files or through messengers, Telegram, Viber, etc.;

4) additional materials, for example, articles, books, hyperlinks; to show various photographs, posters created by students; to store various files downloaded by students and teachers;

5) a seminar directory is a type of extracurricular activity. Students get the ability for peer assessment during the course, as well as the possibility to interact with the teacher, and can also see everything that is happening on a video conference;

6) a lesson directory is a type of activity where learning material is discussed in detail. Students can ask teacher questions or make any suggestions on learning material, and the teacher decides which parts of the lesson should be emphasized in the classroom;

7) tests directory involves materials for self-assessment, students can test their knowledge, and teachers can see the results. The self-assessment may be done in the form of questionnaires, self-study, essays, etc.

This paper has highlighted the importance of the implementation of communicative technology, particularly E-campus into the educational process. As far as digitalization of education and the active use of electronic devices during lessons and independent work is a new stage in the development of the educational process and education system in Ukrainian higher schools in general.

\section{Conclusions}

Considerable progress has been made regarding the implementation of the E-campus for ESP assessment. Our study provides the basis to explore an E-campus that uses a bank of techniques and methods for the formative and summative assessment, assessment criteria for different types of activity in ESP, and that is supported with regulations and methodological recommendations on the use of assessment results.

Our investigations into this area are in progress and seem likely to confirm our hypothesis that each higher school needs to develop an assessment system that includes formative and summative assessment and comprehensively evaluates students' hard and soft skills, shows students' achievements.

We believe that our research will serve as a base for future studies on the creation of such a system in other higher schools of Ukraine. We hope it proves the necessity to develop a technology for formative assessment in other higher schools of Ukraine, which will allow teachers to evaluate the student's achievements in the classroom and during individual work. Our results are encouraging and should be validated by larger sample size. We also open to suggestions and ideas that can help our higher school improve this system to satisfy teachers' needs in the teaching process and students' needs in the learning process.

\section{Acknowledgments}

This research was supported by the Department of English Language for Humanities and Faculty of Linguistics, Igor Sikorsky Kyiv Polytechnic Institute, Ukraine. We also gratefully acknowledge the constructive comments of all students and teachers who participated in the survey.

\section{REFERENCES}

[1] Criteria for Accrediting Engineering Programs, 2018 - 2019, Online available from https://www.abet.org/accreditation/a ccreditation-criteria/criteria-for-accrediting-engineering-pr ograms-2018-2019/

[2] E. Elnajjar, S.-A.B. Al Omari, F. Omar, M. Y.E. Selim, A. Mourad. An Example of Abet Accreditation Practice of Mechanical Engineering Program at UAE University, International Journal for Innovation Education and Research, Vol.7, No 8 (2019), 387-401.

[3] P. Black, D. William. Seven Strategies of Assessment for Learning, Oxford, 2008.

[4] W. Harlen, M. James. Assessment and Learning: differences and relationships between formative and summative assessment, Assessment in Education: Principles, Policy \& Practice, Vol. 4, (1997). No 3, 365-379.

[5] L. A. Shepard. Classroom Assessment to Support Teaching and Learning, The ANNALS of the American Academy of Political and Social Science, Vol. 683, No 1 (2019), 183-200.

[6] A. I. Berman, M. J. Feuer, J.W. Pellegrino. What Use Is Educational Assessment? The ANNALS of the American Academy of Political and Social Science, Vol. 683, No 1 (2019), 8-20.

[7] J. P. Leighton. Students' Interpretation of Formative Assessment Feedback: Three Claims for Why We Know So Little About Something So Important, Journal of Educational Measurement, Vol. 56, No 4 (2019), 793-814.

[8] D. A. Freedman, R. Pisani, R. Purves. Statistics, 4th edition, 2007.

[9] S. Walsh, T. Morton, A. O'Keeffe. Analysing university spoken interaction: A CL/CA approach, International Journal of Corpus Linguistics, Vol. 16(3), 2011, 325-345.

[10] I. Simonova. Assessment preferences and learning styles in ESP, Journal of Language and Cultural Education, Vol. 4(3), 2016, 142-153. 
[11] P. Manoilov, C. Tardieu. Assessment of spoken interactions in two conditions: Teacher-to student versus student-to-student. Language Assessment for Multilingualism., Cambridge University Press, Studies in Language Testing (SiLT), 2014, series hal-01249747f , 490-510.

[12] E. Weigand. The Routledge Handbook of Language and Dialogue. Routledge Taylor \& Francis Group: NY\&London, 2017.

[13] L. Araujo. Computer-based Assessment of Foreign Language Speaking Skills, CBA, 2010.

[14] S-C. Tsai. Implementing interactive courseware into EFL business writing: computational assessment and learning satisfaction, Interactive Learning Environments, Vol. 27, 2019, No 1, 46-61.

[15] T. Dudley-Evans. Developments in English for Specific Purposes: A multidisciplinary approach, Cambridge: Cambridge University Press, 2009.

[16] M. Ronfeldt, S. O. Farmer, K. McQueen, J. A. Grissom. Teacher collaboration in instructional teams and student achievement, American Educational Research Journal, Vol. 52(3) 2015, 475-514.

[17] E. T. Emmer, E. J. Sabornie. Handbook of classroom management (2nd. Ed), New York: Routledge, 2015.

[18] R. Bolitho, R. West. The internationalisation of Ukrainian universities: the English language dimension, Kyiv, «Vydavnytsvo «Stal'», 2017.

[19] S. Borg. The Impact of the English for Universities Project on ESP and EMI in Ukrainian Higher Education, British Council Ukraine, 2019.

[20] J. H. Stronge, T. J. Ward, L. W. Grant. What makes good teachers good? A cross-case analysis of the connection between teacher effectiveness and student achievement, Journal of Teacher Education, Vol. 62(4) 2011, 339-355. 